\title{
Empowering Early Childhood Pre-Service Teachers with Tech Fluency
}

\author{
Rae Ann Hirsh, Keely Baronak \\ Education Department, Carlow University, Pittsburgh, PA, USA \\ Email: rahirsh@carlow.edu, kobaronk@carlow.edu
}

How to cite this paper: Hirsh, R. A., \& Baronak, K. (2020). Empowering Early Childhood Pre-Service Teachers with Tech Fluency. Creative Education, 11, 2730-2748. https://doi.org/10.4236/ce.2020.1112200

Received: October 23, 2020

Accepted: December 19, 2020

Published: December 22, 2020

Copyright ( 2020 by author(s) and Scientific Research Publishing Inc. This work is licensed under the Creative Commons Attribution International License (CC BY 4.0).

http://creativecommons.org/licenses/by/4.0/ (c) (i) Open Access

\begin{abstract}
Many early childhood pre-service teachers will bring some experience with technology into college which may include word processing, gaming, and social media. Some will have a knowledge of block or html programming. Working adult students often bring less experience. Technology in a $21^{\text {st }}$ century elementary classroom integrates technology tools intentionally and ethically. Teachers need to be able to adapt to new technologies and coding languages quickly. Teachers need to embrace the interdisciplinary nature of ScienceTechnology-Engineering-Mathematics (STEM). A complex myriad of tools and strategies exist. This can seem overwhelming and disconnected from the individual disciplinary goals in the classroom. Pre-service teacher preparation programs must empower pre-service teachers with technology fluency in order to respond to fluid and diverse challenges of the $21^{\text {st }}$ century classroom. This exploratory research project synthesizes pedagogy, international technology standards, peer groups, technology trainings, student evaluations, growth mindset theory, and common readers to reform a small liberal arts college's approach to early childhood pre-service teacher preparation. The curriculum revision was guided by these questions: 1) How do our pre-service teachers relate to the present and future worlds of themselves and of their students? 2) How can pre-services programs empower early childhood teachers with tech fluency? The exploration involved undergraduate pre-service teachers over a 6-year period. The research resulted in a five-phase approach to educational technology that consists of Play, Learn, Create, Plan, and Share. Pre-service teachers explore technology tools, learn how they work, create innovative robots and projects from the tools, plan curricula that integrate those tools, and develop agency through sharing their thinking, curricula, and projects with the broader educational community. This approach can offer innovative systemic changes in education technology pedagogy.
\end{abstract}




\section{Keywords}

Early Childhood Education, Educational Technology, STEM, $21^{\text {st }}$ Century

Classroom

\section{Introduction}

Technology tools are often introduced to teachers as 21 st Century teaching tools. Students may have access to specific technologies, but these have not been aligned to 21 st century curriculum outcomes. Without supportive programming, professional development, and curricular alignment, technology sits idle or only serves in a substitution capacity for traditional instructional delivery models. In the early childhood classroom, this is evident as children receive special IPAD or computer time that may or may not be relevant to curriculum outcomes. In contrast to technology used as a reward or a tool to replace traditional instruction, the aim of 21st century technology needs to build technology fluency. Tech fluency empowers the student and teacher to use technology tools to build computational thinking skills, creativity, critical thinking, self-discovery, agency, and intentionality. These are transferrable skills, regardless of the type of technology tool used, that are essential to 21 st century learning. This exploratory research follows a university's six-year journey to re-imagine the role educational technology plays in the early childhood pre-service education program. The re-envisioning of this program began with two questions: 1) How do our pre-service teachers relate to the present and future worlds of themselves and of their students? And 2) How can pre-services programs empower early childhood teachers with tech fluency?

\section{Statement of Problem}

Twenty-first century learning is often synonymous with technology, global competition, Science-Technology-Engineering-Mathematics (STEM), and innovation. The educational community is full of jargon and innovative methods for ensuring preparation for twenty-first century thinking, working, and living.

STEM and innovation are important and noteworthy themes in preparing students for their $21^{\text {st }}$ century future. Twenty-first century technologies have allowed more opportunities for connection and relationships across cultures, generations, and between special interest groups through travel, social media, and access. It is "discovery-centered, interdisciplinary, integrative, translational, and contextual" (Youatt \& Wilcox, 2008: p. 25). However, there are critical skills that are often ignored, especially in college classrooms. Communication, connection, collaboration, responsible citizenship, culture, knowledge democracy and transformation are critical identifiers of twenty-first century learning (Bowen et al., 2017; Couros, 2015; Damhof et al., 2020). 
While technology has the potential for engagement, collaboration, connection, and communication (Kuh \& Nelson Laird, 2005), Bowen et al. (2017: p. 7) reported that "the increase in digital connectivity can also cause isolation because personal interactions and relationships are often sacrificed for individualism." In the college classroom, the isolationism can be reinforced in online environments and onsite environments when students are asked to use technology for independent goals, research, and assignments. To encourage engagement, Kim \& Roth (2008: p. 188) suggest asking this important question "How do students relate to present and future worlds?" The relationships students envision guide the integration of technology in learning. For example, Kim and Roth asked sixth grade Korean students this question and found that children believed technology could "overcome human and environmental problems" and serve as, "a unity of collaborative action with more technology-oriented capacity as an ultimate means to construct a better future" (2008, p. 188). Is this not what we envision technology and innovation to do? This manifestation of technology advocates for development of technology tools to improve human life, existence, and as tools for coping with environmental and societal concerns. Intentionality becomes crucial. When preparing pre-service teachers to facilitate this kind of educational technology mission, it is important to begin with this important question; how do our pre-service teachers relate to the present and future worlds of themselves and of their students?

\subsection{Present World}

How can we use technology and 21st century curriculum as a catalyst for engagement, collaboration, connection, learning, culture, knowledge democracy, and communication to develop social justice themes in the education realm? Carlow University is well-situated to take on such a task. Carlow University was established in 1929 as Mount Mercy College by the Sisters of Mercy to provide higher education to young Catholic women at a time when this was an underserved population in Pittsburgh. Carlow prepares students academically and ethically for competent leadership and compassionate service in personal and professional life. The student population is culturally diverse and comprised of traditional and nontraditional students, more than half of whom are the first in their family to attend college. Approximately $49 \%$ qualify for federal Pell grants provided to students with low family income. The student body is $86 \%$ female, and thus a Carlow University education focuses on the unique learning styles of women, embracing its responsibility to educate women for meaningful work and leadership in their chosen careers.

Carlow's educational technology program is rooted in the university's mission 'to offer transformational educational opportunities for a diverse community of learners and empower them to excel in their chosen work as compassionate, responsible leaders in the creation of a just and merciful world" and emanated through the early childhood education department's mission to "focus on nur- 
turing the dignity, worth, and uniqueness of young children from birth to 4th grade. Young children are vulnerable, impressionable, and filled with beauty and potential. Our job as teachers of young children is to create healthy and nurturing environments and relationships where children can thrive and develop a love of learning. The program is rooted in constructivism, guided by child development pedagogy and early learning standards, and advocates for best 21st century learning practices. Pre-service teachers utilize the National Association for the Education of Young Children's three core considerations when planning learning environments for young children: child development and learning theory, individually appropriateness, and cultural importance. The program develops Pennsylvania Core Knowledge Competencies and Pennsylvania Department of Education's Teacher Certification Competencies." Carlow's early childhood students often work in the field of early childhood education in schools and child care centers, they are first generation college students, and many have struggled with traditional classroom settings as learners. Their experience with technology is usually limited to social media and word processing.

\subsection{Future World}

Many Carlow students view their role in the world as critical to becoming an agent of change; that is usually the draw to a Sisters of Mercy institution. During the first week of class, students are asked why they are at Carlow and why they chose the field of education. Most students talk about the impact they wish to have on the future. They resonate with Carlow's mission to create a "just and merciful world". They are cognizant of the inequities that exist in society, they are advocates for families, they see the world for what it is and envision a better one. They are frustrated with most current educational practices and recognize the need to respond to who children are and who they can become. Part of the frustration stems from a decline of knowledge democracy. Damhof et al. (2020) explain that knowledge democracy "implies acknowledgement of diversity of knowledge systems and cultures. It entails fostering the growth and spread of a diversity of languages, cultures, and practices" (p. 22).

\section{Methodology}

The methodology employed in this research involved ethnographic field work and reflexivity. Ethnographic field work techniques were used during the exploratory phase to observe, gather, and reflect on contextual data regarding training, course projects, dispositions, technology tools, and syllabi development. The primary researchers were both the observed and observer. Mortari (2015: p. 1) explains that reflexivity permits the researcher to actively participate in the research. The researchers were university instructors in the early childhood program that were participating in educational technology professional development while teaching pre-service teachers how to use various technology tools. The theory of reflexivity recognizes that a researcher's inquiry process is shaped 
by a researcher's experience and beliefs. In this case, the researcher's beliefs in learning framed the observations and reactions to the educational technology experiences.

The pre-service students were undergraduate early childhood education majors attending Carlow University, a small Catholic liberal arts college in Pittsburgh, Pennsylvania. Most of the students in the program were first generation college students and receive tuition assistance from state grants and federal loans. Upon completion of the program, students would be eligible for Prek $-4^{\text {th }}$ grade teaching certification in Pennsylvania, United States. Carlow's education program has a unique demographic. Less than half of the students are traditional college students. Many are working adults in their 30's and 40's and a few are above 50. These students had mostly used technology for word processing and social media. They had little experience in coding, robotics, and computational thinking applications.

In 2012, Carlow was the recipient of multiple STEM grants that positioned the education department to engage in research regarding STEM, educational technology, and innovation. As part of this work, Carlow education faculty participated in technology trainings, participated in mathematics training, attended neuroscience conferences, reflected on common readers in innovation, creativity, and learning, engaged with experts in multiple disciplines, and joined the CREATE lab network. CREATE Lab (affiliated with Carnegie Mellon University) is the Community Robotics, Education, and Technology Empowerment Lab and "explores socially meaningful innovation and deployment of robotic technologies" to "...empower a technologically fluent generation ... and empower everyday citizens and scientists...” (Carnegie CREATE Lab, n.d.). Technology tool training was the goal of the educational technology sessions. The math and STEM conferences focused of pedagogy and integrating disciplines. The common readers helped to provide pedagogical discourse and vocabulary for growth mindsets, innovation, creativity, and computational thinking. The CREATE lab network formed an interdisciplinary group of peer educators to explore the intersectionality of STEM, technology tools, pedagogy, dispositions, innovation, creativity, and growth mindsets that evolved into a defining technology fluency.

Previous definitions of technology fluency have focused on computer organizations and hardware, systems and application software, and communications and networks. This definition narrowly focuses technology fluency to specific skills and software (Sardone, 2011). In 2016, The International Society for Technology (2020, n.p.) in Education (ISTE) revised their technology standards as a "framework for innovation to help educators and education leaders thrive in work and life". They introduced additional concepts to technology fluency such as leading, digital citizenship, collaboration, designing, facilitating, and analyzing. The National Association for the Education of Young Children \& Fred Rogers Center for Early Learning and Children's Media at Saint Vincent College (2012) developed a joint position statement to advocate a framework that em- 
phasizes technology's role as tool for connection to children and to families and the intentionality of technology interaction.

As a result of the technology training, national position statements and standards, common readers, and the tech fluency peer group facilitated through CREATE lab, Carlow began to introduce tools with various pedagogical approaches to see how students responded. Students responded with questions and reflections. Dialogue and observations were encouraged and faculty began to cocreate a fluid and dynamic educational technology curriculum.

\section{Analysis and Major Findings}

Themes and best practices emerged from the discussions with students and interactions with the technology tools. Pre-service teachers benefited from didactic and constructivist pedagogy. The pre-service teachers developed more favorable dispositions towards technology if they were given opportunities to explore first without instruction. After students explored and solved some problems on their own, they were receptive to didactic technology training. Once students felt proficient with a particular technology, they needed opportunities to create on their terms-an opportunity for agency. Pre-service teachers began to plan educational technology experiences for children and invited to share their knowledge and plans with peers in the field. The educational technology model-Play-LearnCreate-Plan-Share invites pre-service teachers to explore technology tools, learn how they work, create innovative robots and projects from the tools, plan curricula that integrate those tools, and develop agency through sharing their thinking, curricula, and projects with the broader educational community.

\subsection{Play (Self-Discovery and Engagement)}

In the Disney classic, The Little Mermaid, young mermaid Ariel finds a silver piece deep in the ocean, one of many treasures she found as part of a shipwreck. She takes this piece to Skully, a "wise" old seagull in hopes he can identify it. Holding it up, he proudly announces it's a dinglehopper, used to comb the hairs on your head. In reality, it's a fork. But a fork could be used a comb. We could probably use a fork for a myriad of things, but we are conditioned to think of a fork in a very limited capacity. It's called functional fixedness, a term coined by psychologist Karl Duncker, to describe an inability to see creative applications beyond an object's intended purpose (Duncker, 1945). Functional fixedness is a significant barrier to divergent thinking. And while not synonymous with creativity, divergent thinking is the foundation of it and "as important as literacy" (Do Schools Kill Creativity? Sir Ken Robinson (2015) TED Talks). Young children come by this creative ability naturally. When presented with a simple paperclip and asked to list all the possible ways to use it, young children easily create extensive lists representing great ingenuity. Adults, on average, can only list 5-10 ideas after the obvious function, a paper clip hold papers together (Land \& Jarman, 1992). However, over time, the creative "genius" of children greatly dimi- 
nishes (Do Schools Kill Creativity?|Sir Ken Robsinson|TED Talks, 2015). This in turn impacts divergent thinking and the ability to effectively problem-solve and consider varied iterations of design and creation. Play naturally leads to divergent thinking and problem solving.

Often play is misconstrued as not necessary nor considered real learning. However, significant research has demonstrated time and time again the academic, emotional, dispositional, physical, social, and cognitive benefits of play (Golinkoff et al., 2006; Cole et al., 1978). Play is as essential to childhood as it is to adult learning. College students explore, manipulate, observe, experiment, and reflect on technology tools in the same way students are introduced to other educational materials. Play allows students to take risks and connect with the materials and aids in self-discovery. Play allows for creation and new ideas. Vygotsky explains that in play "things lose their determining force. The child sees one thing but acts differently in relation to what he sees. Thus, a condition is reached in which the child begins to act independently of what he sees" (as cited in Cole et al., 1978: p. 97). Hence, a tool for tackling functional fixedness. This is critical to the development of educational technology, as play encourages unscripted use of technology tools and creates multiple possibilities and agency. Students often uncover a hidden skill, fear, liking or disliking to a specific technology tool. In addition to using play as a vehicle for developing technology skills, play also offers an important conduit for integrating technology tools with other materials. For example, as pre-service students explore block play, they integrate battery powered and solar powered circuit blocks into the play which solidifies the idea that technology is a tool to be used to complete a greater task.

Play allows pre-service teachers to build empathy, problem solve, develop persistence, and take risks-critical skills to developing an innovator's mindset (Couros, 2015). They begin to recognize strengths in one another and begin to connect with materials and with each other. Pre-service teachers at Carlow begin to play with technology tools in a Play as Learning course. In addition to a wide variety of materials, students are introduced to technology tools such as circuit blocks, Squishy Circuits (conductive and insulating dough kit), Finch robots, circuit boards, and other technologies. Students are encouraged to explore, experiment, question, investigate, and play with the various technologies. They are encouraged to think about applications and uses of the tools, what challenges and successes children might have, and how different ages might approach a tool. In play, students create their own problems and strategies for solving them. Problem solving is a crucial skill that is foundational for logical and mathematical development (Hirsh, 2004) and for navigating relationships between people and environments (Greenspan \& Shanker, 2004). In addition, the experience allows students to approach technology through their unique experience and cultural context.

A Carlow senior (R.M., personal communication, 10/2018) explains how powerful the aspect of play is to learning and problem solving, 
Do you remember what it was like to have that childlike wonder? The wonder of how things worked and what they were made up of? So in order to find out you took things apart only to put it back together, but what was different about putting it together is that you now had the knowledge of all the parts and you were the one that put it all back together again. This childlike wonder gets lost as you get older and that had happened to me. I no longer cared how the toaster worked or how to put Legos together. It was all uninteresting for me. I had no desire to take things apart to see what was inside because all I cared about was that the item did what it was built to do. That curiosity had vanished, and I no longer wondered about how things work until we were introduced to circuit boards and programming using the Hummingbird. [Hummingbird is a circuit board designed for children and created by Bird Brain Technologies].

Students then observe children engaging with similar materials in a variety of school contexts. They note similarities and differences between their own explorations and the children they observe.

\subsection{Learn (Collaboration, Connection, and Knowledge Democracy)}

As juniors, students continue their exploration of educational technology tools in math and science methods courses. In these courses, students are introduced to a developmentally appropriate early childhood position statement for using technology and interactive media tools authored by the National Association for the Education of Young Children NAEYC) and the Fred Rogers Center for Early Learning and Children's Media at Saint Vincent College (2012). The position statement provides a developmental framework for technology use with young children which strongly advocates that "effective uses of technology and media are active, hands-on, engaging, and empowering; give the child control; provide adaptive scaffolds to ease the accomplishment of tasks; and are used as one of many options to support children's learning" (National Association for the Education of Young Children \& Fred Rogers Center for Early Learning and Children's Media at Saint Vincent College, 2012: p. 6). Students begin a more in-depth study of various educational technologies by first exploring how they work. Many students use touch screens, computers, APPS, every day, but few understand how these tools work. In the math and science methods courses, students interact with computer programmers to further their own understanding of how these tools work and begin to explore the binary system. Students then use a variety of materials to represent their own understandings of how these tools work before diving into specific educational applications of technology tools. In addition to tools, students develop an understanding of computational thinking. Computational thinking "involves solving problems, designing systems, and understanding human behavior, by drawing on the concepts fundamental to computer science" (Wing, 2006: p. 33). It should be a fundamental 
concept taught to children in support of developing analytic ability (Wing, 2006). Barr, Conery, and Harrsion (2011: p. 20) explain that "The ability to extend the power of human thought with computers and other digital tools has become an essential part of our everyday lives and work. We all need to understand how, when, and where computers and other digital tools can help us solve problems, and we all need to know how to communicate with others". Computational thinking is not limited to computer science. There is a problem-solving process at the heart of computer science. The complexity and analytic thinking involved in this process is valuable across a variety of professions. Computational thinking skills are essential in STEM disciplines (Basu, Mustafaraj, \& Rich, 2016). It is the combination of specific technology tool-use coupled with problem-solving, self-directed learning, and design thinking that empowers computational thinking. Pre-service teachers need to have an understanding of algorithmic problem solving and computational methods and tools to facilitate their foundation in the early childhood years. Young children need to think computationally at an early age to build the necessary foundations for complex concepts, to represent solutions as computational steps, and to solve problems using computational models and methods (Basu, Mustafaraj, \& Rich, 2016).

After students develop computational thinking skills and understand how various technology tools work, they are introduced to block programming with Finch Robots and Hummingbird circuit boards. They explore applications and connections for battery, wind, and solar powered circuit blocks. They explore ways to connect math lessons with Google cardboards and connect APPS such as Stop Motion and HP Reveal to content to provide context to learning activities. During this phase of the program, students begin to work in collaborative teams on various projects. They begin to value skill sets and seek out each other for help and advice. pre-service teachers also begin to connect to the materials and find their comfort zone with specific materials and recognize strengths in one another. This leads to collaborative efforts to deepen technology understanding, use, agency, and intention. This real-world application of technology integrates with formal systems of learning (Damhof et al., 2020).

A Carlow senior explains (R.M., personal communication, 10/2018), "Every single time I had accomplished a task I didn't want to stop there. I wanted to figure out how to take it to the next level and expand on it. To simply put it, I wanted to learn more."

\subsection{Create (Understanding, Evaluation, and Empathy)}

Creativity is pivotal in $21^{\text {st }}$ century education and technology integration. Tsai (2012) explains that "teaching students to think creatively is perhaps the efficacious and comprehensive skill necessary to leading change in the future" (p. 84). Creativity demands opportunities for student-centered learning experiences. In this Create phase, students propose ideas for further learning to inspire integrated technology projects; they lead inquiry, suggest field trips, suggest projects, 
and collaborate for further understanding.

This led to an art robot design challenge and a Digital Petting Zoo project utilizing technology of the student's choice. During one semester, pre-service students asked if they could attend a local STEAM showcase (a local event showcasing Science, Technology, Engineering, Arts, and Mathematics integrative projects in local schools). During this event, the pre-service teachers identified various challenges, projects, field trips, and curricula they wished to explore further in the classroom. Students noticed one of the presenting groups created robots that could produce art. As a class, they decided to engage in a robot design challenge. Students utilized a variety of materials in the education lab to create a robot that produced art. This prompted students to ask, "What is a robot?" which inspired a deep discussion and the students concluded that for this project a robot would be defined as a machine that utilized a technology tool to perform a task. They identified the task as something that produces art. Small groups of students were formed. They created a Morse code machine, mobile magic marker spinner, a modern art maker, magic marker mike, and a splatter robot.

During a different semester, Birdbrain technologies, the creator of the Hummingbird circuit boards the students had learned to use, invited the community to a Digital Petting Zoo project (Figure 1). The pre-service students were very interested in this project and decided to work in small groups to create their own Digital Petting Zoo. Students created their zoo animal using a technology tool in an intentional way to connect to young children. Pre-service teachers created animated animals that could be used in a classroom setting in a variety of ways. Some of these animals were informative and could be used to teach content, some were used for storytelling purposes and as interactive tools for communication, some told jokes and could be used an anticipatory sets, and some were created to respond to environmental stimuli. Students naturally evaluated their work and engaged in intense formative assessment during their work. They engaged in trial and error, failed many times before getting something to work, and began to empathize with the struggles young children might have when they encounter something new for the first time.

\subsection{Plan (Intentionality)}

Technology is a tool to a greater means. The National Association for the Education of Young Children and Fred Rogers Center for Early Learning and Children's Media at Saint Vincent College (2012) explain "Intentionality is key to developmentally appropriate use. One must consider whether the goals can be more easily achieved using traditional classroom materials or whether the use of particular technology and interactive media tools actually extends learning and development in ways not possible otherwise" (p. 8). There is an intentional shift away from technology as an "add-on" consideration. Traditionally, technology integration, or the application of technology to already existing pedagogy and curriculum, has been an accepted pedagogical practice. However, Vallance \& 


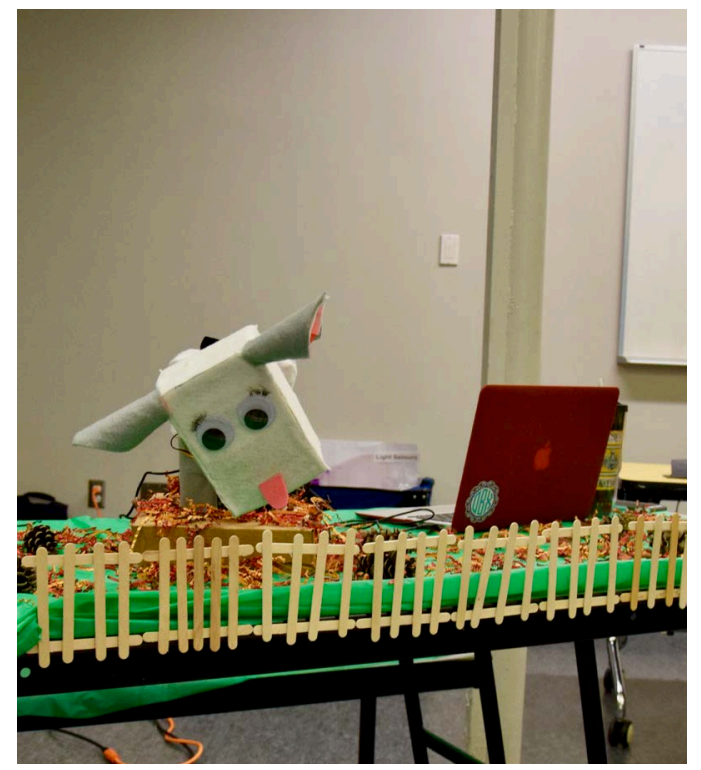

Figure 1. Digital petting zoo.

Towndrow (2016) argue for a less integrated approach positing that classroom activity revolves around problem-solving with computational thinking as knowledge development. It is critical that we address the phenomenon of technology rich but curriculum poor commonly found in economically disadvantaged schools (Ryoo et al., 2013). Schools, teachers, or students may have access to specific technologies, but these have not been aligned to curricular focus, or educators have not intentionally identified them as critical necessities. Without supportive programming, professional development, and curricular alignment, technology sits idle or only serves in a substitution capacity for traditional instructional delivery models. Specificity, intention, and expertise are required by educators in the utilization of technology to establish computational thinking structures in young children (Jaipall, Jamanii, \& Angeli, 2017).

In the methods courses, students begin to bring these tools to children in a variety of school and community contexts in intentional ways. After rich exposure and refinement of technology and programming skills, students enroll in an early childhood curriculum course where they work collaboratively to identify learning goals and incorporate technology tools into a comprehensive STEM curriculum with an emphasis on relationships and intentionality. Students spend the first part of the curriculum class studying various types of curricular approaches. Students identify a curricular topic or theme based on a perceived educational need. They conduct a needs analysis with a designated community of learners. They create goals and objectives and connect them to relevant standards. Students spend time debating the goals and objectives and what sequence makes sense developmentally. When the goals and objectives are agreed upon, students work collaboratively to create a philosophy statement. Formative and summative assessments are identified and integrated into the lesson plans created. As students write the lesson plans, they engage with the materials to 
think about the experiences from a student's perspective. During this class, students are in a practicum setting. They try out various aspects of the curriculum with students and reflect on the success of the experiences and revise the curriculum as needed. The students publish their final curriculum. The students have created curricula on Electricity, Inventions, and Foundational Understandings of Circuit Blocks.

As seniors, students are placed in a practicum setting. Students implement their curriculum in the practicum setting and reflect on its success. The curricula are also copied for the University's Lab School whose teachers use and evaluate the curriculum in their classrooms.

\subsection{Share (Communication, Professionalism, and Empowerment)}

Pre-service teachers have the potential for bringing in new and different technologies in student teaching and teaching settings. They can develop as leaders in this work and professionally present their ideas, tools, and curricula. An important part of pre-service educational technology is developing the soft skills necessary to collaborate, present, and share digital knowledge and expertise with children, colleagues, parents, and administrators. Students in this program also engage with the community on various educational activities that use technology tools. In this phase, students develop specialized projects from learning outcomes and implement the projects in a community-based setting. One such project was work with a Cub Scout Troop. A second grade Cub Scout troop visited the university to work on a STEM badge. The pre-service students were instructed to create an engaging lesson using an educational technology that fit within the STEM badge's objectives.

One group created a game board for the Finch. Cub Scouts needed to program the Finch to navigate the board. In order to do this, they needed to ask questions about building sequences and expressions. They needed to experiment. They failed frequently as they laughed and engaged in problem solving for having their Finch make it to the end of the game board. The group worked collaboratively to figure out the commands and sequence they needed to navigate the board successfully (Figure 2).

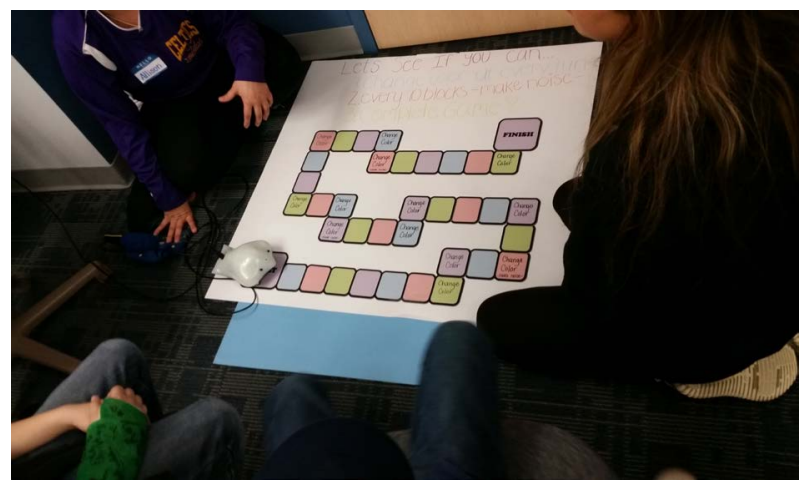

Figure 2. Finch game board. 
A former graduate student reflects on her Finch project (A.R., personal communication, 10/2018),

I was initially intimidated by the Finch technology, but I was also intrigued about working with the cub scouts. As a group, my peers and I developed a simple game board that would challenge the scouts to use the different functions of the Finch technology with math strategies that they have learned throughout school. I immersed myself into learning and understanding how the finch operated, I became invested in mastering the game board myself so I could explain the concept to the scouts. I became passionate about my preparation and knowledge for the technology and our game board. This project allowed students to work collaboratively to problem solve. This program gave me an opportunity to learn new technology and merge schoolbased strategies and content to create engaging lessons for school age children. They worked together to solve the programming challenges. The finch technology forced me to reach out of my comfort zone to develop something innovative that was inspiring to learn and to teach.

Another group hid a Pirate treasure somewhere in the computer lab. The scouts were given a treasure map and a series of commands for finding the treasure. The students had to work together to use the cues to create successful commands. They failed many times. But each failure brought the group closer together with the support and encouragement of the student group.

A senior reflects on the scout experience (K.H., personal communication, 10/ 2018),

I had the opportunity to teach a local cub scout troop how to program the Finch robot. I saw the boys one night for a couple hours, and they were able to understand the program perfectly. We set up a challenge for the children and gave them a pirate map in a bottle. They had to use the map to direct the robot where to go. They programmed the robot to turn at certain times and which way to move. Once they programed it to go through every aspect of the map, they found the treasure and found a prize. The boys loved the activity and were so proud to say that they were programming a robot. The most rewarding part was how engaged the boys were in the block programming.

Another project was a Digital Petting Zoo using the Hummingbird circuit board or Finch robot using a visual programming language created by CREATE lab. The Digital Petting Zoo was a collaborative project where students worked in small groups to create an interactive animal designed to connect with young children. The project was difficult and required application of many skills, persistence, risk, patience, and time. pre-service teachers spend many lab hours programming their digital pet. They argued and debated with one another, experimented, and failed many times. At the conclusion of the project, students had created dynamic interactive Digital Pets. As they mastered difficult pro- 
gramming tasks, their self-confidence increased, and they felt empowered to try innovative ways to use the technology.

A Senior (K.S., personal communication, 10/2018) reflects on her Finch project:

The project I created was a three-part simple story about a duck that needed to take a birthday gift to her friend, a frog (Figure 3). The idea was to use the tool to engage students as young as Preschool in the project. The robot would act out the story and reveal and speak the storyline while the students could listen to the story and interact with the story that was created. I thought about how the abilities of the children would allow them to take more control of the different elements such as the literacy, artistic expression, and technological coding and sequencing steps. A favorite literacy curriculum of mine is Vivian Paley's storytelling curriculum where the child is able to tell a story and the teacher is able to write down the details of the story, retell the story, and help the child bring their story to life. The child is then able to act out the story and choose classmates to act out the various parts. Now I had a tool that could allow us to expand on this using technology! I used this same concept to introduce 1st, 2nd, and 3rd grade students to Puerto Rico during a culture's unit. The robot was dressed up the coqui frog and took them on a tour of Puerto Rico via a map I created on the floor. They were so excited to listen to and watch the robot. They were so excited to share their own experiences, what they learned, and wanted to use the tool to create their own projects. What I loved about this technology was that it had so many components that could be modified and adapted to the independent learner. One student I worked with was non-verbal and this robot could give him the voice to express himself creatively and socially just by typing in the words into the text to speech expression. Another student could work on their math concepts with the robot as the narrator of the math story. The setting could be created to fit any infinite number of habitats and help to engage students in creating ecological systems and expressing both through words and actions the exploration of that environment.

After sharing these experiences with children, the students decided to share their work with other students. They decided to present their Digital Petting Zoo during Carlow's Undergraduate Scholarship Day. This is an annual event where undergraduates showcase research, project, and other scholarly work. The Digital Petting Zoo exhibit was designed as an interactive demonstration where audience members could freely walk through the projects and engage with students. In addition to the university community, the creators and software developers of the various technologies from CREATE lab also attended. The students were able to interact with the designers of these technologies and discuss classroom applications.

The students also had an opportunity to share their work internationally. A Chinese delegation of educators visited CREATE lab satellites and projects. 


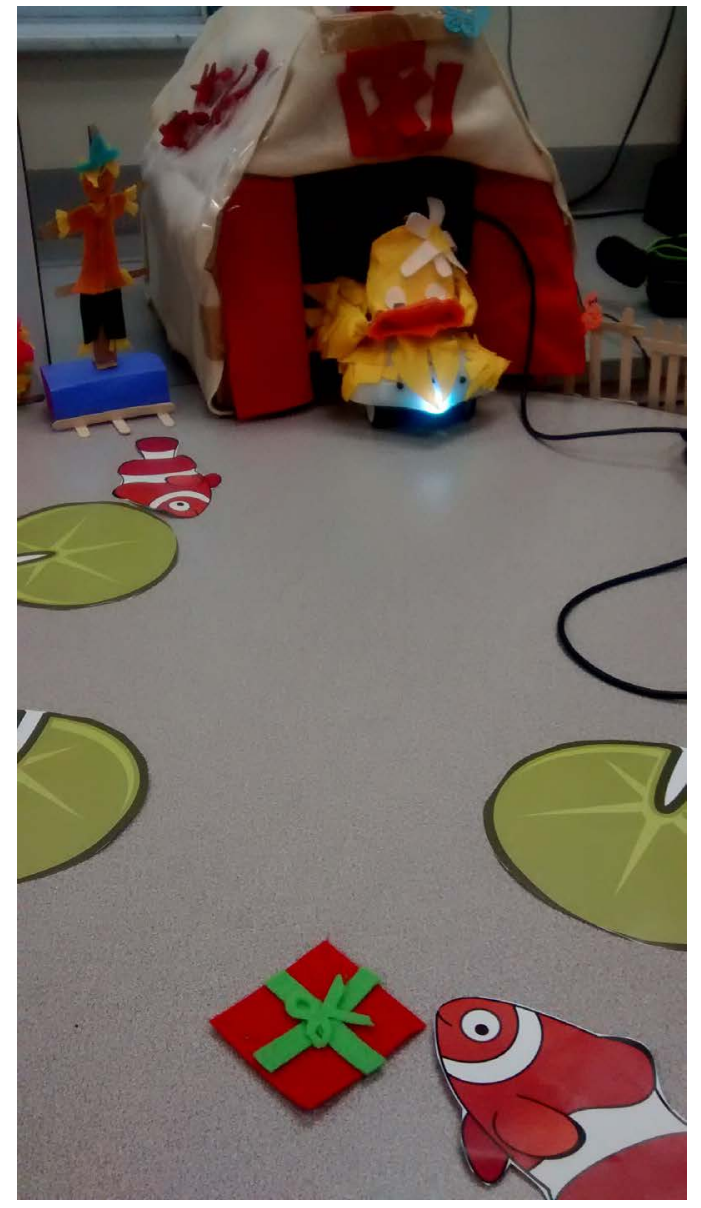

Figure 3. Finch storytelling.

Students were asked to share their projects and most volunteered. The delegates shared equity and access issues with Carlow students and discussed international applications of their work with the delegates

The following academic year, this same group of students volunteered to submit their Digital Petting Zoo and curriculum projects at the annual CREATE lab CONTEXT conference. At the CONTEXT conference, students had the opportunity to showcase their projects, present their classroom applications of the technologies, and share their skills, successes, and failures, and interact with classroom teachers, other instructors, and, STEM faculty, and administrators.

Each time the students presented their work and interacted with the audience, their professionalism, reflection, articulation, and engagement with the work grew immensely in quality. Their understanding of their own work and the implications of their work evolved with each audience and presentation.

A senior (R.M., personal communication, 10/2018) summarizes her experiences with the educational technology program:

That is what we strive as educators for our students. Our goal is to have them want to learn. We want them to explore, expand, ask questions and have hands on opportunities which is why each school should have one be- 
cause it not only helps students with learning technology, but it expands on other skills and provides them with a desire to gain knowledge and apply it. I saw so much growth in myself from when I first started with the robots to where I am now. I used to be terrified of STEM opportunities because mathematics is not my strong suit, but little did I know that just because I was avoiding opportunities in mathematics. I was also avoiding other STEM related activities including robotics. Presently, I have worked with a group of Cub Scouts for two years on various robotic projects. I never imagined myself to be so comfortable with a STEM activity and now I know that activities such as these I can incorporate into my own future classroom. Working with the robotics gave me confidence in myself as a future educator and it brought back that childlike wonder that I had missed so much.

\section{Recommendations for Empowering Pre-Service Educators}

The field of education in the $21^{\text {st }}$ century integrates technology tools intentionally and ethically and teachers need to be able to adapt to new technologies and coding languages quickly. This can seem overwhelming and disconnected from the individual disciplinary goals in the classroom. A $21^{\text {st }}$ century pre-service technology curriculum is multi-faceted and integrated. At Carlow University, students needed more than tools and skills to be adept to teach in contemporary school programs. Pre-service teachers needed to Play, Learn, Create, Plan, and Share technology integration throughout the four years they attended their undergraduate program in order to develop technology fluency. Technology is a process. It is not simply learning a tool to integrate into a classroom. By the time pre-service teachers are in the field, many of the tools they have learned in a pre-service program will be upgraded, obsolete, or new tools will exist. Children's understanding and use of technology tools are changing as well. New skill sets will be necessary in the future. Instead of limiting technology preparation to skills and tools, pre-service teachers need to be empowered with the skills necessary to navigate a $21^{\text {st }}$ century technology classroom.

Empower pre-service teachers with confidence and comfortability by providing opportunities to experiment, play, and explore. Taking risks in a low-risk environment where students are not afraid to fail is critical to $21^{\text {st }}$ century education. Innovation is born from risk, not from a safety net.

Empower pre-service teachers with agency by providing opportunities to create projects and share work with others. Pre-service teachers can conduct professional development workshops, speak at conferences, develop training and curriculum materials, and organize STEM events. Their choice of audience promote agency. Carlow students chose workshops, student clubs, girls scout and boy scout troops, other teachers in informal CREATE lab discussions, or a group of international delegates interested in educational technology to share their tools, processes, and understandings.

Empower pre-service teachers with innovation and creativity through choice, 
opportunities to take risk, and the ability to design projects and lesson plans.

Empower pre-service teachers through computational thinking and data analysis by providing opportunities to use formal and informal data to improve their project and lesson plans.

Empower pre-service teachers with professionalism by providing opportunities to integrate standards from professional organizations into their work.

Empower pre-service teachers with compassion and empathy by providing preservice teachers opportunities to struggle, fail, and develop a growth mindset.

Once pre-service teachers have been empowered as technology fluent stewards, they are able to adapt to new technologies, use tools to create or problem solve, integrate and plan opportunities to use tools, and share tools with parents, children, administrators, and other educators. Damhof et al. (2020) caution that "societies will need to find ways of adapting to new conditions that are going to affect all lives. These changes are the consequences of myriad phenomena, including climate change, demographic shifts and movements, longer lifespans, technological progress, the developing globalized economy, and continuing or newly emerging social and cultural divisions" (p. 24). Developing tech fluency skills in both pre-service teachers and young children can serve the needs of future generations and to be able to empower young children with the skills, tools, mindsets, and computational thinking skills necessary to live, work, play, and transform the future.

\section{Acknowledgements}

Thanks to Allison Hyradil, Kristina Hudock, Rachel Makary, and Kalei Smith.

\section{Conflicts of Interest}

The authors declare no conflicts of interest regarding the publication of this paper.

\section{References}

Barr, D., Harrison, J., \& Conery, L. (2011). Computational Thinking: A Digital Age Skill for Everyone. International Society for Technology in Education, 38, 20-23. https://eric.ed.gov/?id=EJ918910

Basu, S., Mustafaraj, E., \& Rich, K. (2016). Computational Thinking. https://circlcenter.org/computational-thinking

Bowen, G., Gordon, N., \& Chojnacki, M. (2017). Advocacy through Social Media: Exploring Student Engagement in Addressing Social Issues. Journal of Higher Education Outreach and Engagement, 21, 5. https://eric.ed.gov/?id=EJ1156183

Carnegie Mellon CREATE lab. (n.d.). http://www.cmucreatelab.org/

Cole, M., John-Steiner, V., Scribner, S., \& Souberman, E. (1978). Mind in Society: The Development of Higher Psychological Processes.

http://ouleft.org/wp-content/uploads/Vygotsky-Mind-in-Society.pdf

Couros, G. (2015). The Innovator's Mindset: Empower Learning, Unleash Talent, and Lead a Culture of Creativity. San Diego: Dave Burgess Consulting, Inc. 
Damhof, L., Kazemier, E., Gulmans, J., Cremers, P., Doornbos, A., \& Beenen, P. (2020). Anticipation for Emergence: Defining, Designing and Refining Futures Literacy in Higher Education. In Humanistic Futures of Learning: Perspectives from UNESCO Chairs and UNITWIN Networks. Paris: Unesco.

Duncker, K. (1945). On Problem Solving (L.S. Lees, Trans). Psychological Monographs, 58, i-113. https://doi.org/10.1037/h0093599

Golinkoff, R. M., Hirsh-Pasek, K., \& Singer, D. G. (2006). Why Play=Learning: A Challenge for Parents and Educators. In D. G. Singer, R. M. Golinkoff, \& K. Hirsh-Pasek (Eds.), Play=Learning: How Play Motivates and Enhances Children's Cognitive and Social-Emotional Growth (pp. 3-12). Oxford: Oxford University Press. https://doi.org/10.1093/acprof:oso/9780195304381.003.0001

Greenspan, S., \& Shanker, S. (2004). The First Idea: How Symbols, Language, and Intelligence Evolved Form our Primate Ancestors to Modern Humans. Cambridge, MA: Capo Press.

Hirsh, R. (2004). Early Childhood Curriculum: Incorporating Multiple Intelligences, Developmentally Appropriate Practice, and Play. Boston, MA: Pearson.

International Society for Technology (2020). ISTE Standards. https://www.iste.org/standards

Jaipal-Jamani, K., \& Angelia, C. (2017). Effect of Robotics on Elementary Preservice Teachers' Self-Efficacy, Science Learning, and Computational Thinking. Journal of Science Education and Technology, 26, 175-192.

https://doi.org/10.1007/s10956-016-9663-Z

Kim, M., \& Roth, W. (2008). Envisioning Technological Literacy in Science Education: Building Sustainable Human-Technology-Lifeworld Relationships. Journal of Educational Thought, 42, 185-206. https://doi.org/10.11575/jet.v42i2.52466

Kuh, G. D., \& Nelson Laird, T. (2005). Student Experiences with Information Technology and Their Relationship to Other Aspects of Student Engagement. Research in Higher Education, 46, 211-233. https://doi.org/10.1007/s11162-004-1600-y

Land, G., \& Jarman, B. (1992). Breakpoint and Beyond: Mastering the Future Today. New York, NY: Harpercollins Publishers.

Mortari, L. (2015). Reflectivity in Research Practice: An Overview of Different Perspectives. International Journal of Qualitative Methods, 14, 1-9. https://doi.org/10.1177/1609406915618045

National Association for the Education of Young Children \& Fred Rogers Center for Early Learning and Children's Media at Saint Vincent College (2012). Technology and Interactive Media Tools in Early Childhood Programs Serving Children from Birth through Age 8 .

https://www.naeyc.org/sites/default/files/globally-shared/downloads/PDFs/resources/t opics/PS_technology_WEB.pdf

Robinson, K. (2015). Do Schools Kill Creativity? Sir Ken Robinson, Ted Talks. https://www.youtube.com/watch?v=iG9CE55wbtY

Ryoo, J. J., Margolis, J., Lee, C. H., Sandoval, C. D. M., \& Goode, J. (2013). Democratizing Computer Science Knowledge: Transforming the Face of Computer Science through Public High School Education. Learning, Media and Technology, 38, 161-181. https://doi.org/10.1080/17439884.2013.756514

Sardone, N. (2011). Developing Information Technology (IT) Fluency in College Students: An Investigation of Learning Environments and Learner Characteristics. Journal of Information Technology Education, 10, 101-122.

https://doi.org/10.28945/1381 
Tsai, K. C. (2012). The Value of Teaching Creativity in Adult Education. International Journal of Higher Education, 1, 84-91. https://doi.org/10.5430/ijhe.v1n2p84

Wing, J. (2006) Computational Thinking. Communications of the ACM, 49, 33-35. https://cs.cmu.edu/ 15110-s13/Wing06-ct.pdf https://doi.org/10.1145/1118178.1118215

Youatt, J., \& Wilcox, K. A. (2008). Intentional and Integrated Learning in a New Cognitive Age: A Signature Pedagogy for Undergraduate Education in the Twenty-First Century. Peer Review, 10, 24-26.

https://www.aacu.org/sites/default/files/files/peerreview/PRFall08.pdf 